\title{
Embankment Seismic Fragility Assessment under the Near-Fault Pulse-like Ground Motions by Applying the Response Surface Method
}

\author{
Fa Che, ${ }^{1,2}$ Chao Yin $\left(\mathbb{D},{ }^{1,3,4}\right.$ Jilei Zhou ${ }^{1},{ }^{5}$ Zhinan $\mathrm{Hu}^{3}$ Xingkui Zhao, ${ }^{6}$ Lu Sheng, \\ Qian Zhang, ${ }^{6}$ Xiaoyu Cheng, ${ }^{7}$ Gangting Tang, ${ }^{1}$ Han Zhang, ${ }^{1}$ and Dong Liu ${ }^{8}$ \\ ${ }^{1}$ School of Civil and Architecture Engineering, Shandong University of Technology, Zibo 255049, China \\ ${ }^{2}$ Zibo Transportation Service Center, Zibo 255000, China \\ ${ }^{3}$ State Key Laboratory of Mechanical Behavior and System Safety of Traffic Engineering Structures, \\ Shijiazhuang Tiedao University, Shijiazhuang 050043, China \\ ${ }^{4}$ Key Laboratory of Roads and Railway Engineering Safety Control (Shijiazhuang Tiedao University), Ministry of Education, \\ Shijiazhuang 050043, China \\ ${ }^{5}$ School of Transportation and Vehicle Engineering, Shandong University of Technology, Zibo 255049, China \\ ${ }^{6}$ Shandong Dongtai Engineering Consulting Co., Ltd., Zibo 255000, China \\ ${ }^{7}$ Zibo International Academy at High-Tech Zone, Zibo 255000, China \\ ${ }^{8}$ Laoling Branch of Dezhou Highway Development Center, Dezhou 253000, China
}

Correspondence should be addressed to Chao Yin; yinchao@sdut.edu.cn and Jilei Zhou; zhj1521@sdut.edu.cn

Received 11 May 2020; Revised 29 December 2020; Accepted 3 March 2021; Published 25 March 2021

Academic Editor: Said Elias

Copyright ( $) 2021 \mathrm{Fa}$ Che et al. This is an open access article distributed under the Creative Commons Attribution License, which permits unrestricted use, distribution, and reproduction in any medium, provided the original work is properly cited.

\begin{abstract}
Uncertainties of the ground motions and structural parameters are the main factors that limit the accuracy of embankment seismic fragility assessment. In response to the uncertainties of the ground motions, artificial synthesizing method of the nearfault pulse-like ground motions was proposed, and 15 ground motions with the rupture fault distances ranging from 1 to $15 \mathrm{~km}$ were synthesized by taking the Chi-Chi earthquake in Taiwan, China, as an example. The Xi'an-Baoji expressway K1125 + 470 embankment was taken as the research object, and a total of 12 structural parameters were selected as the design variables, namely, the elastic modulus, bulk modulus, shear modulus, density, cohesion force, and internal friction angle of the embankment fill and soil foundation, respectively. In response to the uncertainties of these parameters, 3 principal components with large impacts on the embankment seismic fragility were extracted based on the principal component analysis. Mapping relationships among the principal components and embankment seismic damages were analyzed using the uniform design response surface method, and the seismic fragility assessment was carried out and the fragility curves were plotted. The research results are consistent with the actual embankment seismic damage conditions of the Chi-Chi earthquake, indicating that the proposed method is scientific and reasonable. It also shows that it would obviously overestimate the seismic performance in the embankment seismic fragility assessment without considering the uncertainties of the ground motions and structural parameters.
\end{abstract}

\section{Introduction}

Strong earthquakes have occurred frequently in the world; for example, the 2004 Sumatra earthquake in Indonesia, the 2008 Wenchuan earthquake in China, the 2010 earthquakes in Haiti and Chile, the 2011 east Japan earthquake, and the 2017 Jiuzhaigou Valley's earthquake in China resulted in severe structural damages, causing major human casualties and economic losses [1-3]. Near-fault ground motions generally occur at sites located near active faults and are characterized by the following main features: (1) large amplitude and long-period velocity pulses; (2) high Peak Ground Velocity/Peak Ground Acceleration (PGV/PGA) and Peak Ground Displacement/Peak Ground Acceleration 
(PGD/PGA) ratios; and (3) concentration of energy in one or few pulses. The pulse-like ground motions are caused primarily by the forward directivity effect, which are observed at a site when the fault rupture propagates towards the site with a velocity close to shear wave velocity [4-6]. The near-fault ground motions with long-period pulses have much more energies input to long-span linear structures than the far-fault ground motions. Therefore, researches on the fragility assessment of structures such as embankments under the near-fault pulse-like ground motions are of great significance for performance-based seismic design [7-9].

Uncertainties of the ground motions and structural parameters are the main factors that limit the accuracy of the seismic fragility assessment $[10,11]$. The uncertainties of the ground motions are influenced by aleatory uncertainties (uncertainty due to the random nature of the processes under consideration such as ground motion record-to-record variability) and epistemic uncertainties (uncertainty due to incomplete knowledge and data such as model parameter uncertainty, omissions, and errors) [12-15]. There are two main methods to solve the problem of the uncertainties of the ground motions. The first selects the actual recorded ground motions provided by the Pacific Earthquake Engineering Research Center (PEER). For example, Yin et al. [16] selected 15 ground motions in medium-hard sites to carry out the embankment seismic fragility assessment and verified the impact of the retaining wall on improving the embankment seismic performance. Bao et al. [17] selected 10 near-fault ground motions and 10 far-fault ground motions to carry out the fragility assessment of the nuclear reactor shell structure under the main shock and aftershocks, respectively. Li et al. [7] investigated the dynamic response characteristics of the $1 / 30$ scale model of the Wuhan Shimao Center subjected to the El Centro wave and Taft wave by analyzing the shaking table test data. He et al. [18] adopted 22 actual recorded ground motions according to the recommendations of the Applied Technology Council (ATC) in the FEMA P695 report in the seismic fragility analysis of multiage buried steel pipes. Since it is difficult to find the ground motions that fully comply with the lithology properties of where the structure is located and with the law of seismic wave propagation, the accuracy of the seismic fragility assessment based on actual recorded ground motions is relatively low $[19,20]$. The second is synthesizing ground motions. For example, Sheng et al. [21] calculated the fragility indexes of the frequent earthquake, fortification earthquake, and rare earthquake of group structures combined with the synthesized ground motions and empirical earthquake damage indexes. Salami et al. [22] carried out the seismic fragility assessment of low-rise reinforced concrete structures under the main shock and aftershocks based on the synthesized ground motions. Abyani et al. [23] used a genetic algorithm to analyze the impact of the number of synthesized ground motions on the fragility assessment results of jacket offshore platforms. For near-fault pulse-like ground motions, the maximum values of the parameters in different directions vary significantly. For example, Yang and Zhou [24] studied the impacts of the pulse-like ground motions on the response spectrum in different directions and pointed out that the ground motions on the strongest pulse direction comprehensively considered the impacts of the pulse period, peak velocity, and duration, and the energies input to the structure were maximized. However, existing artificial near-fault ground motion models do not take into account the directivity of pulse-like ground motions in history analysis, and the seismic performance may be overestimated in the seismic fragility assessment [15, 25-27].

Some scholars ignore the impacts of the uncertainties of the structural parameters on the seismic performance and build models using deterministic values directly, while some introduce the response surface method to characterize the mapping relationships among the structural parameters and seismic responses [28]. There are 3 steps of the seismic fragility assessment based on the response surface method: (1) experimental design, that is to determine the sample points and structural response values [29]; (2) select the response surface function that meets the structural functional requirements [30]; and (3) fit the response surface function and verify the model accuracy [31, 32]. For example, Saha et al. [33] used the Monte Carlo method to study the discreteness of the parameters of the tank structure and carried out the seismic fragility assessment based on the response surface method. $\mathrm{Li}$ and $\mathrm{Li}$ [29] proposed a uniform design response surface method to study the impacts of the multiple correlations of the design variables on the bridge seismic fragility. Tran et al. [34] carried out the seismic fragility assessment of nuclear power plants based on the response surface method and plotted the fragility curves by the maximum likelihood estimation method and linear regression method, respectively. Since the response surface functions often take the form of summation of several complete polynomials, when there are too many structural parameters, the applicability of the model greatly reduces and the solution of the response surface function tends to fall into a "curse of dimensionality" [30, 35-37].

In view of this, the Xi'an-Baoji expressway K1125+470 embankment was taken as the research object, the stochastic pulse models with different rupture fault distances were established by considering the directional impacts of the pulse-like ground motions, and the linear correlation of the structural parameters was eliminated based on the principal component analysis. In addition, embankment seismic fragility assessment using 15 artificial pulse-like ground motions with the rupture fault distances ranging from 1 to $15 \mathrm{~km}$ was carried out by applying the response surface method, aiming to provide a theoretical basis for the performance-based design of embankment.

\section{Artificial Synthesizing Method of the Near- Fault Pulse-Like Ground Motions}

Since the orientation of the apparatus in a seismic station is arbitrary, the recorded ground motions at the time of the earthquake are not necessarily the maximum, especially for the near-fault pulse-like ground motions, the seismic intensities in different directions are obviously different [38]. In this paper, the linear combination of the continuous 
wavelet transformation results of two horizontal components (fault-normal velocity history and fault-parallel velocity history) of the pulse-like ground motions was used to build the motion model on the strongest pulse direction, and the following methods were applied for stochastic modeling and artificial synthesizing of the near-fault pulse-like ground motions [24, 26, 39-41]:

(1) Apply wavelet transformation to synthesize the faultnormal velocity history and fault-parallel velocity history of the pulse-like ground motions into the velocity history on the strongest pulse direction and divide the velocity history into low-frequency components and high-frequency components.

(2) Fit the low-frequency components using the Gabor wavelet analytic function and propose the correlations among the pulse parameters, i.e., seismic moment, rupture fault distance and site condition, and seismological parameters. The regression model between the PGV on the strongest pulse direction and rupture fault distance is calculated, and the lowfrequency stochastic pulse function is established after obtaining the probability distribution of the low-frequency pulse parameters.

(3) Differentiate the residual velocity history containing the high-frequency components to obtain the residual acceleration history and employ the improved Kanai-Tajimi power spectrum model to fit the statistical power spectrum containing the high-frequency components to obtain the power spectrum parameters.

(4) Use the envelope function to fit the residual acceleration history after Hilbert transformation to reflect the nonstationarity of the high-frequency components and obtain the probability distribution of the corresponding envelope parameters via statistics.

(5) Generate the velocity history of the near-fault pulselike ground motions by superimposing the longperiod velocity pulse and velocity history with the high-frequency components and obtain the acceleration history through differentiation, as shown in Figure 1.

The pulse-like ground motions of the station CHY080 of the Chi-Chi earthquake on September 21, 1999, in Taiwan, China, were adopted to synthesize 15 ground motions with the rupture fault distances ranging from 1 to $15 \mathrm{~km}$, respectively. The rupture fault distance of the CHY080 station

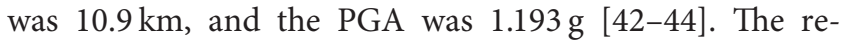
gression model between the PGV on the strongest pulse direction and rupture fault distance was calculated according to the recorded ground motions, as shown in Figure 2.

For the synthesized ground motions were generated from the same earthquake event, i.e., Chi-Chi earthquake, the magnitude $M_{w}=7.6$ was not included in the regression model. The standard deviation $\sigma_{1}$ reflects epistemic modeling uncertainty regarding the factors controlling variety of
PGVs with the same rupture fault distance $R$ and follows a log-normal distribution. A representative sample under the scenario of rupture fault distance $R=15 \mathrm{~km}$ was used to generate the synthesized ground motions according to Figure 1, as shown in Figure 3. It is indicated that the synthetic velocity history represents the pulse characteristic of the near-fault ground motions properly, and the corresponding acceleration history can be used as the stochastic excitation input for the embankment seismic fragility assessment. It is worth noting that the seismic fragility assessment in this paper is only based on the Chi-Chi earthquake, and the results are valid for earthquakes with the same characteristics as the Chi-Chi earthquake.

\section{Response Surface Method}

3.1. Embankment Model. FLAC can simulate structures made of soil, rock, and other materials that flow plastically when reaching their yield limits [45]. FLAC adopts the finite difference scheme to solve the governing differential equation, which can accurately simulate the yield, plastic flow, softening, and large deformation of materials, especially has unique advantages in the fields of elastic-plastic analysis, large deformation analysis, and simulation of construction process [46]. A finite difference model of the embankment fill-soil foundation system of the research object was established by using FLAC. The width of the embankment fill was $24.5 \mathrm{~m}$, the left side was $6.1 \mathrm{~m}$ high, the right side was $2.6 \mathrm{~m}$ high, and the slope ratio was $1: 1.5$. The slope of the soil foundation was $24^{\circ}$, the thickness was $30 \mathrm{~m}$, and the width was $120 \mathrm{~m}$. Among them, the vehicle loads have been converted to the thickness of the embankment fill according to the elastic layer theory, as shown in Figure 4.

A total of 12 structural parameters were selected as the design variables, namely, the elastic modulus, bulk modulus, shear modulus, density, cohesion force, internal friction angle of the embankment fill, and soil foundation. Considering the uncertainties of the material sources and construction qualities, the values of the above parameters were highly random [29]. According to the geological survey data of the Xi'an-Baoji expressway, the laboratory test results of the embankment fill and soil foundation, and other existing researches [18, 47], the elastic modulus, bulk modulus, shear modulus, cohesion force of the embankment fill and soil foundation followed the log-normal distribution; the density, internal friction angle of the embankment fill, and soil foundation followed the normal distribution; the probability distribution parameters of these structural parameters are shown in Table 1, and the probability distribution curves of these structural parameters are shown in Figure 5.

\subsection{Selection of the Embankment Seismic Damage Parameter.} According to Song et al. [48] and Li et al. [49], PGA is selected as the intensity parameter of the ground motions, and the embankment seismic damage levels are divided into 5 grades: basically intact, minor damage, moderate damage, severe damage, and destruction. Since the embankment is a 


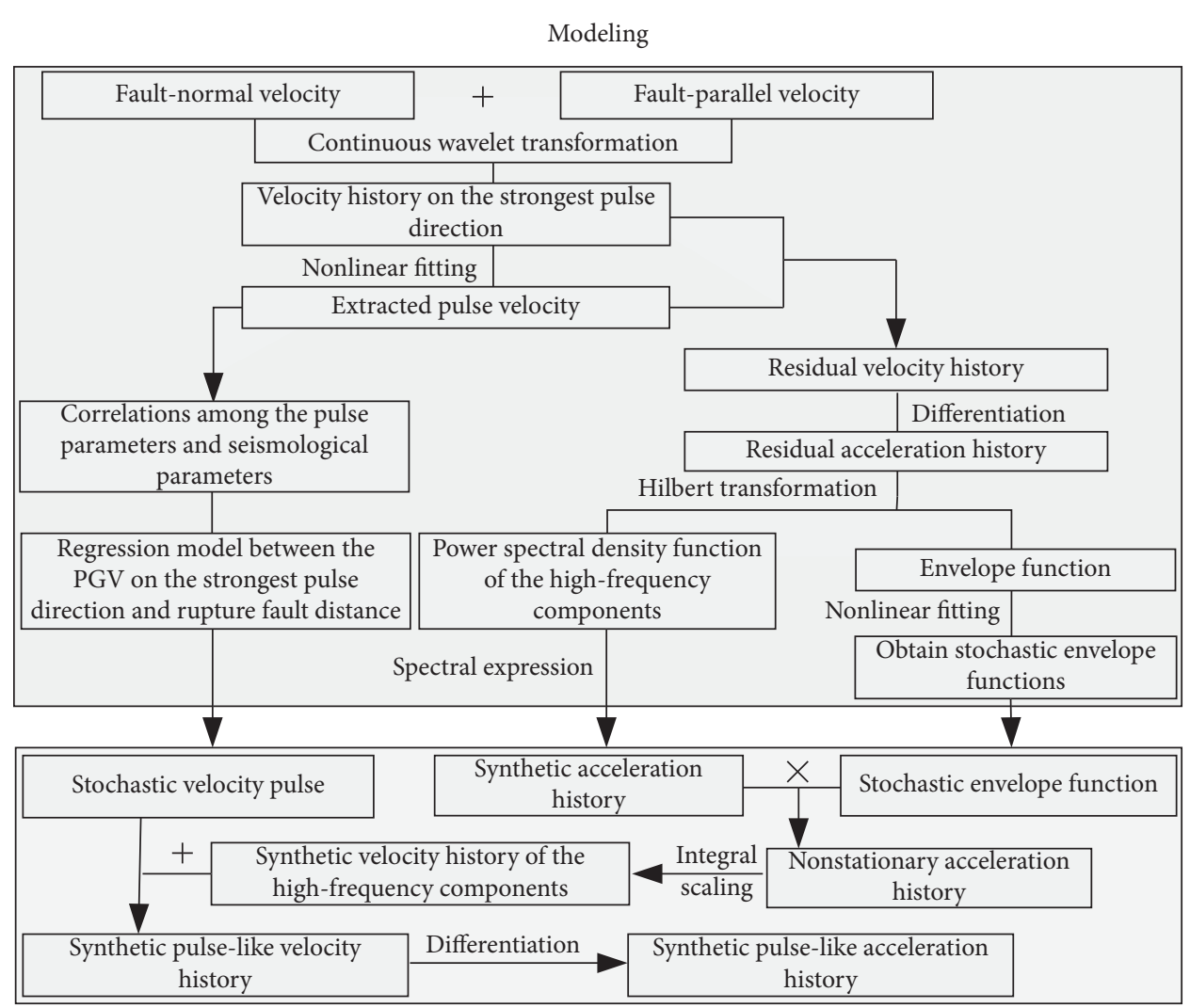

Synthesizing

FIgURE 1: Stochastic modeling and artificial synthesizing method of the near-fault pulse-like ground motions.

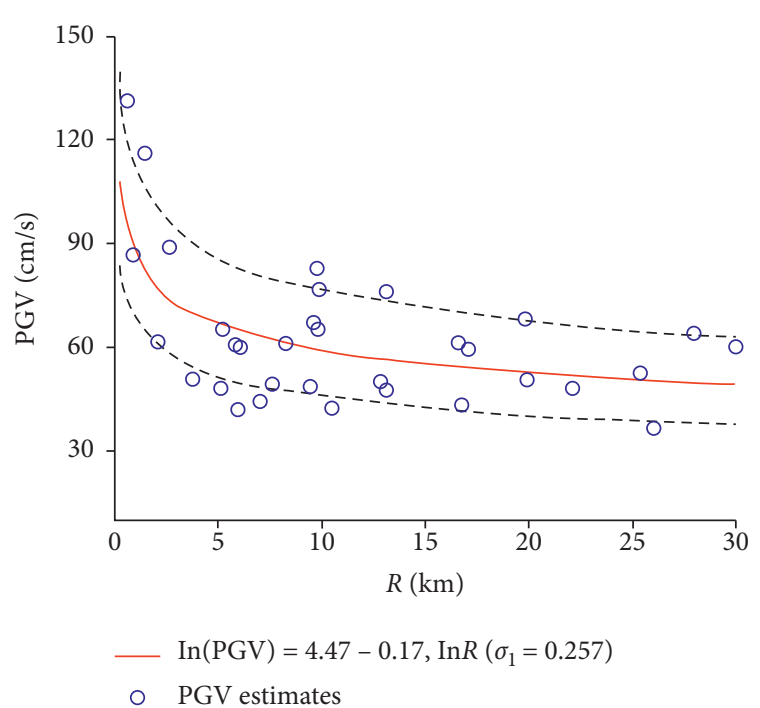

Figure 2: Attenuation of PGV with the rupture fault distance $R$ for the Chi-Chi earthquake (the dashed lines correspond to mean values $\left.\pm \sigma_{1}\right)$.

statically indeterminate structure, damages caused by earthquakes would be reflected by the displacement. Therefore, $\varepsilon_{\max }$ is selected as the embankment seismic damage parameter based on the displacement failure criterion, and the calculation method of $\varepsilon_{\max }$ is shown in the following equation:

$$
\varepsilon_{\max }=100\left(\frac{d_{\max }}{D}\right)
$$

where $d_{\max }$ is the lateral maximum permanent displacement on the top surface of the embankment and $D$ is the embankment width; $D=24.5 \mathrm{~m}$. According to the investigation results of the Wenchuan earthquake, embankments at the epicenter (Yingxiu town) suffered from the most severely damage, i.e., destruction, and $\varepsilon_{\max }$ reached $2.059 \%$ [50-52]; therefore, considering $\varepsilon_{\max }=2.0 \%$ as the boundary of severe damage and destruction was reasonable. Besides, the boundaries of $\varepsilon_{\max }$ among other embankment seismic damage grades were further established based on the equidistant classifying method $[17,53]$, as summarized in Table 2.

3.3. Principal Component Analysis Results. Since the solution of the response surface function easily falls into a "curse of dimensionality" when there are too many structural parameters and the parameters may not be linearly independent, the principal component analysis was used to reduce the number of variables $[36,54]$. According to the probability distribution parameters listed in Table 1, 10,000 sets of structural parameter combinations were randomly generated via MATLAB. Due to the different dimensions and vast differences in data amplitude of the structural parameters, data normalization was conducted before further 


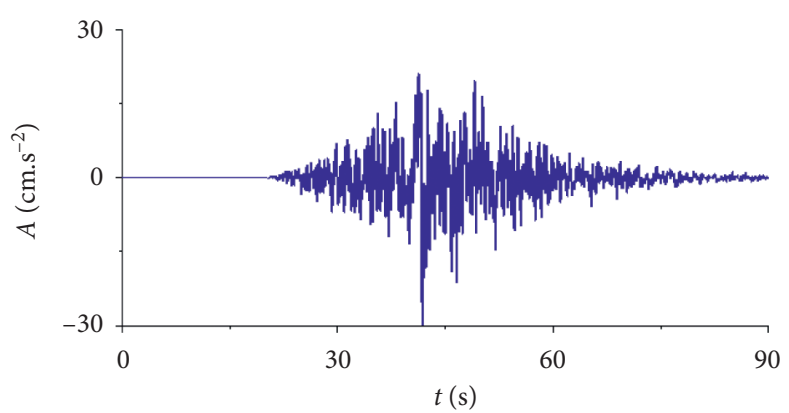

(a)

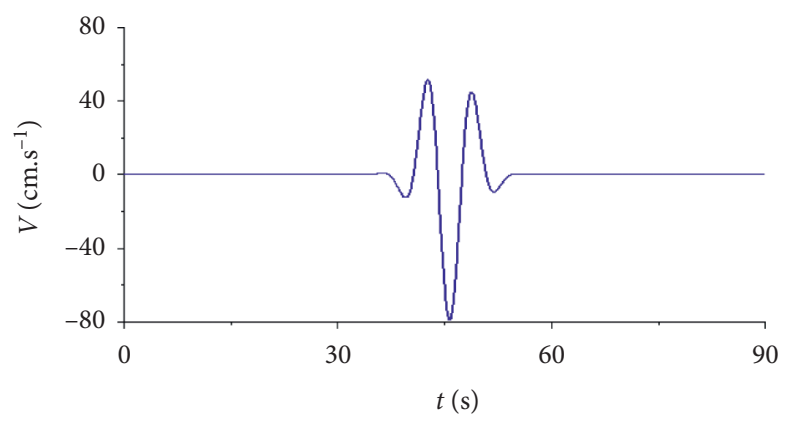

(c)

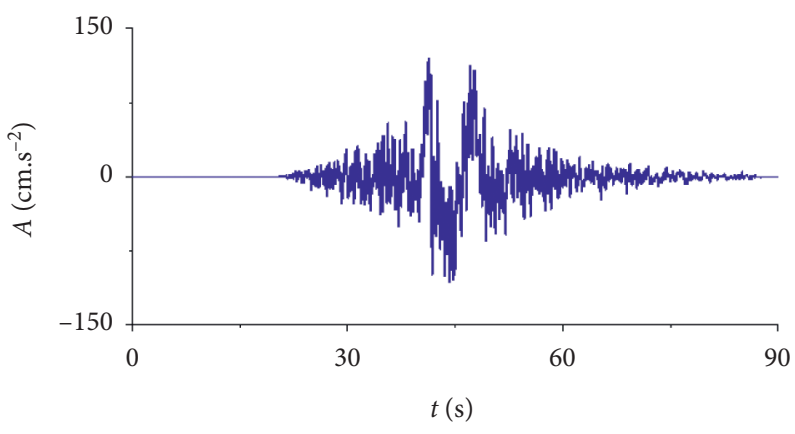

(e)

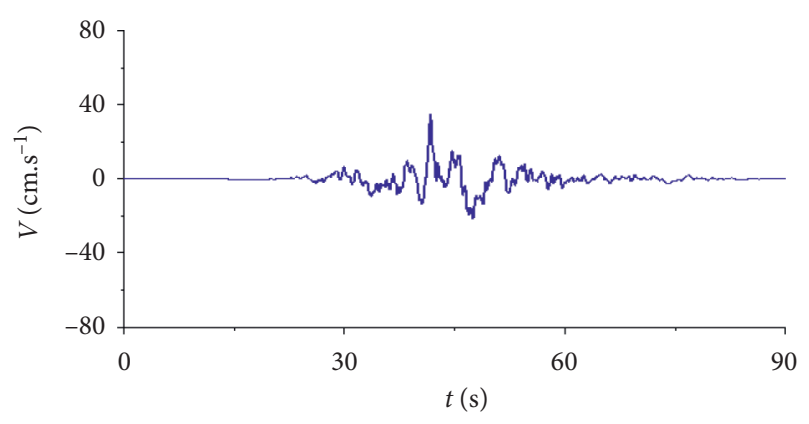

(b)

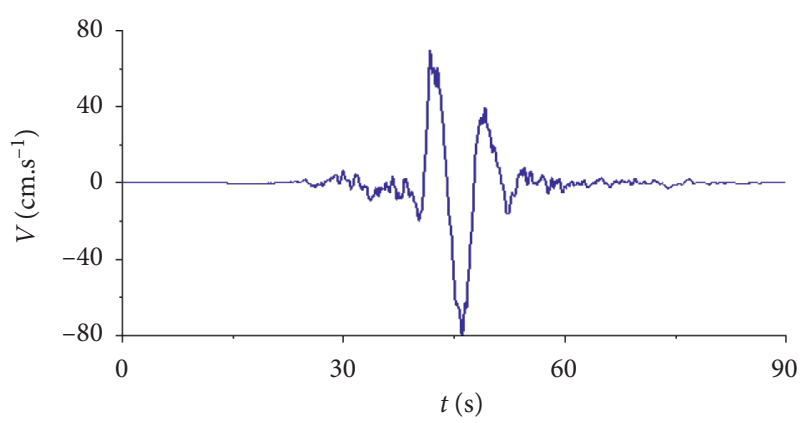

(d)

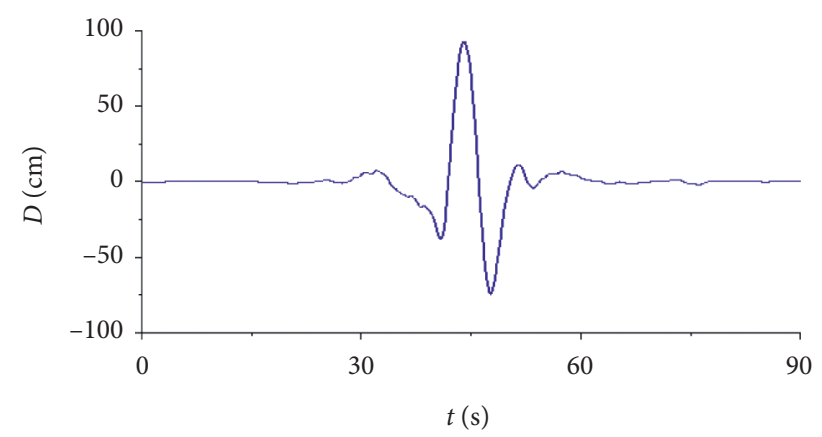

(f)

Figure 3: Artificial synthesizing results of the pulse-like ground motion with the rupture fault distance $R=15 \mathrm{~km}$. (a). Acceleration history of high-frequency components. (b) Velocity history of high-frequency components. (c) Random velocity pulse. (d) Pulse-like velocity history. (e) Synthetic acceleration history. (f) Synthetic displacement history.

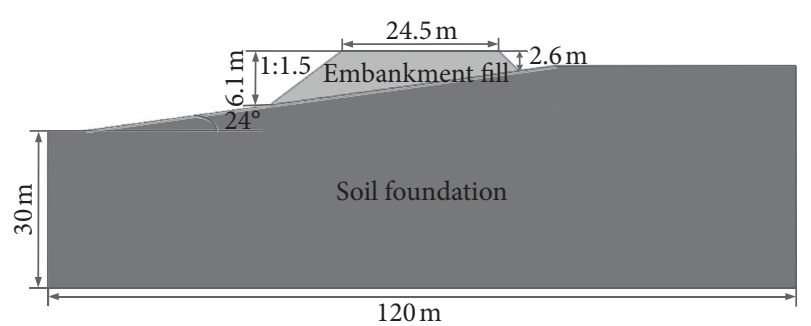

Figure 4: Embankment model.

calculations. The calculation method is shown in the following equation:

$$
v\left(X_{i}^{n}\right)=\frac{2\left(X_{i}^{n}-u_{X_{i}}\right)}{X_{i \max }-X_{i \min }}
$$

where $X_{i}$ is the $i$ th structural parameter, $i$ is a natural number from 1 to $12, X_{i \max }$ and $X_{i \min }$ are the maximal and minimal values of $X_{i}$, and $u_{X_{i}}$ is the average value of $X_{i}$, as shown in Table $1 . X_{i}^{n}$ is the $n$th value of $X_{i}, n$ is a natural number from 1 to $10000, v\left(X_{i}^{n}\right)$ is the normalized value of $X_{i}^{n}$, and $v\left(X_{i}^{n}\right) \epsilon$ $[-1,1]$. The correlation coefficient $\rho_{i j}$ of $v\left(X_{j}\right)$ and $v\left(X_{j}\right)$ is calculated according to the following equation:

$$
\begin{aligned}
\rho_{i j} & =\frac{\operatorname{COV}\left(v\left(X_{i}\right), v\left(X_{j}\right)\right)}{\sigma_{v\left(X_{i}\right)} \cdot \sigma_{v\left(X_{j}\right)}} \\
& =\frac{E\left[\left(v\left(X_{i}^{n}\right)-\mu_{v\left(X_{i}\right)}\right) \cdot\left(v\left(X_{j}^{n}\right)-\mu_{v}\left(X_{j}\right)\right)\right]}{\sigma_{v\left(X_{i}\right)} \cdot \sigma_{v\left(X_{j}\right)}},
\end{aligned}
$$

where $\mu_{v\left(X_{j}\right)}, \sigma_{v\left(X_{i}\right)}, \mu_{v\left(X_{j}\right)}$, and $\sigma_{v\left(X_{j}\right)}$ are the mean values and standard deviations of $v\left(X_{i}\right)$ and $v\left(X_{j}\right)$, respectively, and 
TABLe 1: Probability distribution parameters of the structural parameters.

\begin{tabular}{lcccc}
\hline Sequence numbers & Structural parameters & Distribution patterns & Mean values & Coefficients of variation \\
\hline$X_{1}$ & Elastic modulus of the embankment fill & Log-normal distribution & $48.00 \mathrm{MPa}$ & 0.20 \\
$X_{2}$ & Elastic modulus of the soil foundation & Log-normal distribution & $42.00 \mathrm{MPa}$ & 0.20 \\
$X_{3}$ & Bulk modulus of the embankment fill & Log-normal distribution & $50.00 \mathrm{MPa}$ & 0.20 \\
$X_{4}$ & Bulk modulus of the soil foundation & Log-normal distribution & $43.75 \mathrm{MPa}$ & 0.20 \\
$X_{5}$ & Shear modulus of the embankment fill & Log-normal distribution & $17.91 \mathrm{MPa}$ & 0.33 \\
$X_{6}$ & Shear modulus of the soil foundation & Log-normal distribution & $15.67 \mathrm{MPa}$ & 0.33 \\
$X_{7}$ & Density of the embankment fill & Normal distribution & $1970 \mathrm{~kg} / \mathrm{m}^{3}$ & 0.20 \\
$X_{8}$ & Density of the soil foundation & Normal distribution & $1630 \mathrm{~kg} / \mathrm{m}^{3}$ & 0.20 \\
$X_{9}$ & Cohesion force of the embankment fill & Log-normal distribution & $34.00 \mathrm{kPa}$ & 0.20 \\
$X_{10}$ & Cohesion force of the soil foundation & Log-normal distribution & $31.00 \mathrm{kPa}$ & 0.20 \\
$X_{11}$ & Internal friction angle of the embankment fill & Normal distribution & $33.00^{\circ}$ & 0.20 \\
$X_{12}$ & Internal friction angle of the soil foundation & Normal distribution & $28.00^{\circ}$ & 0.20 \\
\hline \multicolumn{7}{c}{} & & &
\end{tabular}

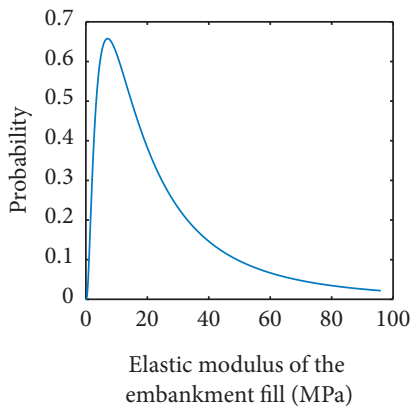

(a)

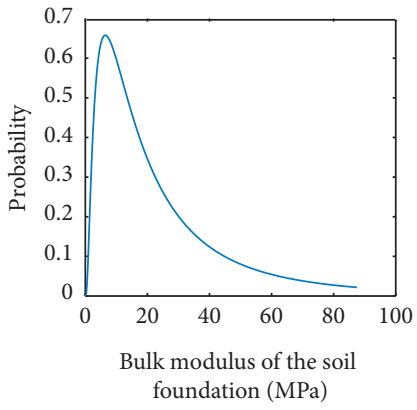

(d)

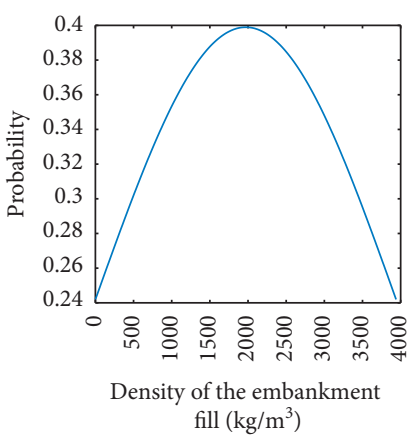

(g)

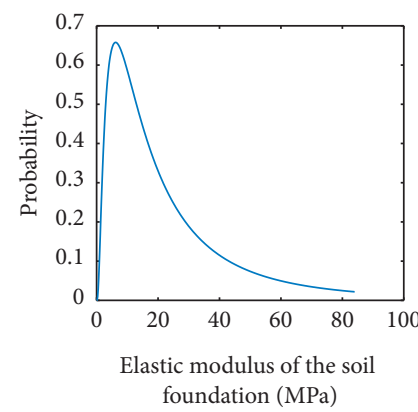

(b)

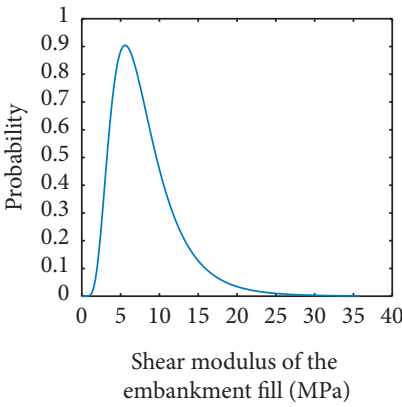

(e)

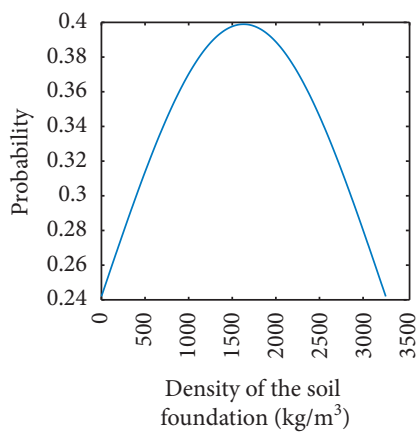

(h)

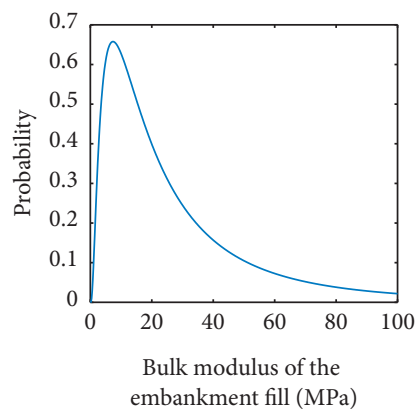

(c)

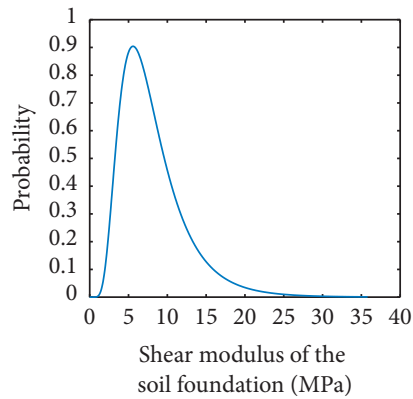

(f)

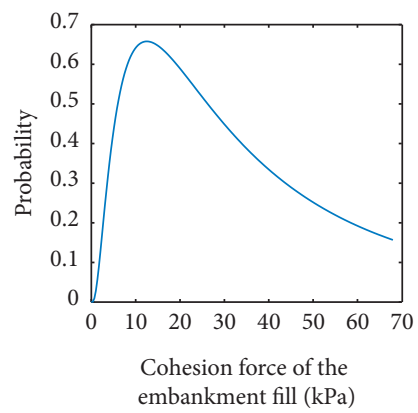

(i)

Figure 5: Continued. 


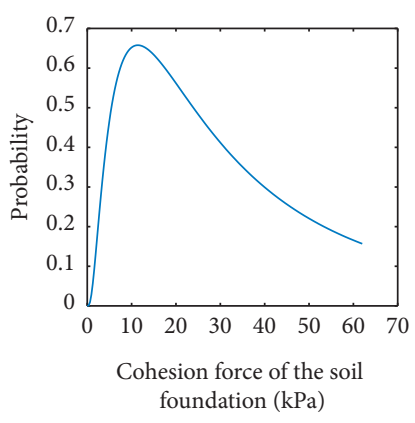

(j)

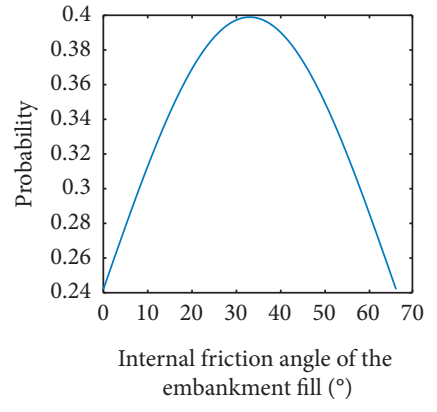

$(\mathrm{k})$

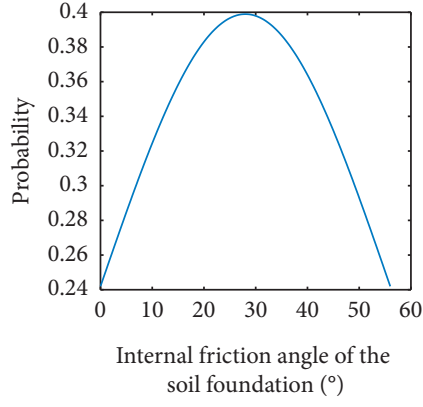

(l)

FIgURE 5: Probability distribution curves of the structural parameters.

TABLE 2: Boundaries of $\varepsilon_{\max }$ among the embankment seismic damage grades.

\begin{tabular}{lccccc}
\hline Embankment seismic damage grades & Basically intact & Minor damage & Moderate damage & Severe damage & Destruction \\
\hline$\varepsilon_{\max }$ & $0 \leq \varepsilon_{\max }<0.3$ & $0.30 \leq \varepsilon_{\max }<0.60$ & $0.60 \leq \varepsilon_{\max }<1.20$ & $1.20 \leq \varepsilon_{\max }<2.00$ & $\varepsilon_{\max } \geq 2.00$ \\
\hline
\end{tabular}

other symbols have the same meaning. The calculation results are shown in Table 3.

The weight vector, eigenvalue, original information contribution rate, and cumulative original information contribution rate of each structural parameter corresponding to the principal component were further calculated based on SPSS22.0, and 3 principal components $F_{1}, F_{2}$, and $F_{3}$ were extracted according to the eigenvalue not less than 1 , as shown in Table 4.

The equations of $F_{1}, F_{2}$, and $F_{3}$ are shown in equations (4)-(6) according to Table 4.

$$
\begin{aligned}
F_{1}= & 0.156 v\left(X_{1}\right)+0.591 v\left(X_{2}\right)+0.062 v\left(X_{3}\right)-0.043 v\left(X_{4}\right)+ \\
& 0.238 v\left(X_{5}\right)-0.227 v\left(X_{6}\right)-0.114 v\left(X_{7}\right)+0.963 v\left(X_{8}\right)+ \\
& 0.814 v\left(X_{9}\right)+0.798 v\left(X_{10}\right)+0.208 v\left(X_{11}\right)-0.109 v\left(X_{12}\right), \\
F_{2}= & -0.701 v\left(X_{1}\right)+0.113 v\left(X_{2}\right)+0.798 v\left(X_{3}\right)+0.884 v\left(X_{4}\right)- \\
& 0.170 v\left(X_{5}\right)+0.249 v\left(X_{6}\right)+0.182 v\left(X_{7}\right)-0.048 v\left(X_{8}\right)+ \\
& 0.197 v\left(X_{9}\right)-0.201 v\left(X_{10}\right)+0.198 v\left(X_{11}\right)+0.234 v\left(X_{12}\right), \\
F_{3}= & 0.307 v\left(X_{1}\right)-0.198 v\left(X_{2}\right)-0.095 v\left(X_{3}\right)+0.113 v\left(X_{4}\right)+ \\
& 0.817 v\left(X_{5}\right)+0.917 v\left(X_{6}\right)-0.243 v\left(X_{7}\right)-0.132 v\left(X_{8}\right)+ \\
& 0.039 v\left(X_{9}\right)+0.135 v\left(X_{10}\right)-0.816 v\left(X_{11}\right)+0.295 v\left(X_{12}\right),
\end{aligned}
$$

The following conclusions can be obtained from equations (4) to (6):

(1) F1 mainly reflects the elastic modulus, density, and cohesion force of the soil foundation, and the cohesion force of the embankment fill; F2 mainly reflects the elastic modulus and bulk modulus of the embankment fill, and the bulk modulus of the soil foundation; F3 mainly reflects the shear modulus and internal friction angle of the embankment fill, and the shear modulus of the soil foundation.

(2) When $X_{1}$ to $X_{12}$ all take the mean values, $F_{1}, F_{2}$, and $F_{3}$ can also take the mean value 0 . When $X_{4}, X_{6}, X_{7}$, and $X_{12}$ take the minimal values and other structural parameters take the maximal values, $F_{1}$ takes the maximal value, or otherwise, the minimal value. When $X_{1}, X_{8}$, and $X_{10}$ take the minimal values and other structural parameters take the maximal values, $F_{2}$ takes the maximal value, or otherwise, the minimal value. When $X_{2}, X_{3}, X_{7}, X_{8}$, and $X_{11}$ take the minimal values and other structural parameters take the maximal values, $F_{3}$ takes the maximal value, or otherwise, the minimal value.

3.4. Calculation Results of the Response Surface Method. Mapping relationships between $\varepsilon_{\max }$ and $F_{1}, F_{2}, F_{3}, \mathrm{PGA}$, and standard deviation $\sigma_{2}$ of $\varepsilon_{\max }$ and $F_{1}, F_{2}, F_{3}$, PGA were 
TABLE 3: Correlation coefficient matrix $\rho_{i j}$ of $v\left(X_{i}\right)$ and $v\left(X_{j}\right)$.

\begin{tabular}{|c|c|c|c|c|c|c|c|c|c|c|c|c|}
\hline$\rho_{i j}$ & $v\left(X_{1}\right)$ & $v\left(X_{2}\right)$ & $v\left(X_{3}\right)$ & $v\left(X_{4}\right)$ & $v\left(X_{5}\right)$ & $v\left(X_{6}\right)$ & $v\left(X_{7}\right)$ & $v\left(X_{8}\right)$ & $v\left(X_{9}\right)$ & $v\left(X_{10}\right)$ & $v\left(X_{11}\right)$ & $v\left(X_{12}\right)$ \\
\hline$v\left(X_{1}\right)$ & 1 & & & & & & & & & & & \\
\hline$v\left(X_{2}\right)$ & 0.279 & 1 & & & & & & & & & & \\
\hline$v\left(X_{3}\right)$ & 0.501 & 0.099 & 1 & & & & & & & & & \\
\hline$v\left(X_{4}\right)$ & 0.376 & -0.197 & 0.742 & 1 & & & & & & & & \\
\hline$v\left(X_{5}\right)$ & 0.106 & 0.083 & 0.203 & 0.234 & 1 & & & & & & & \\
\hline$v\left(X_{6}\right)$ & -0.099 & -0.104 & 0.297 & 0.137 & 0.138 & 1 & & & & & & \\
\hline$v\left(X_{7}\right)$ & 0.042 & 0.097 & -0.251 & -0.074 & -0.056 & -0.076 & 1 & & & & & \\
\hline$v\left(X_{8}\right)$ & 0.075 & 0.104 & 0.105 & 0.96 & 0.271 & 0.134 & 0.157 & 1 & & & & \\
\hline$v\left(X_{9}\right)$ & -0.087 & -0.038 & 0.218 & -0.033 & 0.103 & 0.254 & 0.046 & 0.864 & 1 & & & \\
\hline$v\left(X_{10}\right)$ & 0.043 & -0.103 & -0.548 & 0.257 & 0.095 & -0.358 & -0.185 & 0.358 & 0.654 & 1 & & \\
\hline$v\left(X_{11}\right)$ & -0.075 & -0.097 & 0.087 & -0.159 & -0.278 & 0.545 & 0.104 & -0.567 & -0.149 & -0.452 & 1 & \\
\hline$v\left(X_{12}\right)$ & -0.389 & 0.080 & 0.364 & 0.242 & -0.152 & -0.221 & 0.289 & 0.325 & 0.312 & 0.489 & 0.545 & 1 \\
\hline
\end{tabular}

TABLe 4: Principal component analysis results of the structural parameters.

\begin{tabular}{|c|c|c|c|c|}
\hline \multirow{2}{*}{ Calculation results } & \multirow{2}{*}{ Normalized values } & \multicolumn{3}{|c|}{ Principal components } \\
\hline & & $F_{1}$ & $F_{2}$ & $F_{3}$ \\
\hline \multirow{12}{*}{ Weight vectors } & $v\left(X_{1}\right)$ & 0.156 & -0.701 & 0.307 \\
\hline & $v\left(X_{2}\right)$ & 0.591 & 0.113 & -0.198 \\
\hline & $v\left(X_{3}\right)$ & 0.062 & 0.798 & -0.095 \\
\hline & $v\left(X_{4}\right)$ & -0.043 & 0.884 & 0.113 \\
\hline & $v\left(X_{5}\right)$ & 0.238 & 0.170 & 0.817 \\
\hline & $v\left(X_{6}\right)$ & -0.227 & 0.249 & 0.917 \\
\hline & $v\left(X_{7}\right)$ & -0.114 & 0.182 & -0.243 \\
\hline & $v\left(X_{8}\right)$ & 0.963 & -0.048 & -0.132 \\
\hline & $v\left(X_{9}\right)$ & 0.814 & 0.197 & 0.039 \\
\hline & $v\left(X_{10}\right)$ & 0.798 & -0.201 & 0.135 \\
\hline & $v\left(X_{11}\right)$ & 0.208 & 0.198 & -0.816 \\
\hline & $v\left(X_{12}\right)$ & -0.109 & 0.234 & 0.295 \\
\hline Eigenvalues & 6.274 & 3.128 & 1.574 & \\
\hline Original information contribution rates & $54.385 \%$ & $29.667 \%$ & $9.578 \%$ & \\
\hline Cumulative original information contribution rate & $93.630 \%$ & & & \\
\hline
\end{tabular}

calculated based on the uniform design response surface method [17], as shown in the following equations:

$$
\begin{aligned}
\varepsilon_{\max }= & \alpha_{0}+\alpha_{1} F_{1}+\alpha_{2} F_{2}+\alpha_{3} F_{3}+\alpha_{4} P G A+\alpha_{5} F_{1}^{2}+\alpha_{6} F_{2}^{2}+\alpha_{7} F_{3}^{2}+\alpha_{8} P G A^{2}+\alpha_{9} F_{1} F_{2} \\
& +\alpha_{10} F_{1} F_{3}+\alpha_{11} F_{1} P G A+\alpha_{12} F_{2} F_{3}+\alpha_{13} F_{2} P G A+\alpha_{14} F_{3} P G A+\varepsilon_{1}, \\
\sigma_{2}= & \beta_{0}+\beta_{1} F_{1}+\beta_{2} F_{2}+\beta_{3} F_{3}+\beta_{4} P G A+\beta_{5} F_{1}^{2}+\beta_{6} F_{2}^{2}+\beta_{7} F_{3}^{2}+\beta_{8} P G A^{2}+\beta_{9} F_{1} F_{2} \\
& +\beta_{10} F_{1} F_{3}+\beta_{11} F_{1} P G A+\beta_{12} F_{2} F_{3}+\beta_{13} F_{2} P G A+\beta_{14} F_{3} P G A+\varepsilon_{2},
\end{aligned}
$$

where $\alpha_{0}-\alpha_{14}, \beta_{0}-\beta_{14}$ are undetermined coefficients and $\varepsilon_{1}$ and $\varepsilon_{2}$ are regression coefficients of $\varepsilon_{\max }$ and $\sigma_{2}$, respectively. The main object of this paper was to reveal the dynamic response regulars of the embankment under the near-fault pulse-like ground motions with different rupture fault distances.

In dynamic response analysis, more accurate results are often obtained when more than one earthquake are used, but according to the stochastic modeling and artificial synthesizing method of the near-fault pulse-like ground motions, it is necessary to calculate the attenuation relationship of PGV with the rupture fault distance, which requires a large number of seismic records [55]. In this paper, we calculated the attenuation relationship of Chi-Chi earthquake with $M_{w}=7.6$, and the 15 synthesized ground motions generated from the Chi-Chi earthquake were employed to the dynamic response analysis and the results were valid for earthquakes with the same characteristics [56]. Dynamic response analysis based on more earthquakes would be conducted in future researches. Since the PGA of the Chi-Chi earthquake was $1.193 \mathrm{~g}$, three values of $0.2 \mathrm{~g}, 0.7 \mathrm{~g}$, and $1.2 \mathrm{~g}$ were assumed to cover the recorded PGA of the Chi-Chi 
TABLE 5: Dynamic response analysis results of the embankment.

\begin{tabular}{|c|c|c|c|c|c|c|}
\hline \multirow[t]{2}{*}{ Sequence numbers } & \multirow[t]{2}{*}{$F_{1}$} & \multirow[t]{2}{*}{$F_{2}$} & \multirow[t]{2}{*}{$F_{3}$} & \multirow[t]{2}{*}{ PGA/g } & \multicolumn{2}{|c|}{$\begin{array}{l}\text { Mean values and standard deviations } \sigma_{2} \text { of } \\
\varepsilon_{\max }\end{array}$} \\
\hline & & & & & Mean values & Standard deviations $\sigma_{2}$ \\
\hline 1 & -4.323 & -3.975 & -4.107 & 1.2 & 1.8056 & 0.4752 \\
\hline 2 & -4.323 & 0 & 4.107 & 0.2 & 0.2824 & 0.0754 \\
\hline 3 & -4.323 & 3.975 & 0 & 0.7 & 0.8637 & 0.2153 \\
\hline 4 & -4.323 & -3.975 & 0 & 0.7 & 0.7418 & 0.1980 \\
\hline 5 & -4.323 & 0 & 4.107 & 1.2 & 1.9211 & 0.4990 \\
\hline 6 & -4.323 & 3.975 & -4.107 & 0.2 & 0.2157 & 0.0568 \\
\hline 7 & -4.323 & -3.975 & 4.107 & 1.2 & 2.0770 & 0.5327 \\
\hline 8 & -4.323 & 0 & 0 & 0.2 & 0.3043 & 0.0770 \\
\hline 9 & 0 & 3.975 & -4.107 & 0.7 & 0.9218 & 0.2364 \\
\hline 10 & 0 & -3.975 & 4.107 & 0.2 & 0.2195 & 0.0543 \\
\hline 11 & 0 & 0 & 0 & 1.2 & 1.8689 & 0.4658 \\
\hline 12 & 0 & 3.975 & 0 & 0.2 & 0.2885 & 0.0763 \\
\hline 13 & 0 & -3.975 & 4.107 & 0.7 & 0.8517 & 0.2129 \\
\hline 14 & 0 & 0 & 0 & 0.7 & 0.7061 & 0.1834 \\
\hline 15 & 0 & 0 & -4.107 & 1.2 & 2.0792 & 0.5172 \\
\hline 16 & 0 & 3.975 & 4.107 & 0.2 & 0.3712 & 0.0928 \\
\hline 17 & 0 & -3.975 & 0 & 0.7 & 0.9107 & 0.2397 \\
\hline 18 & 0 & 0 & 0 & 0.2 & 0.2967 & 0.0771 \\
\hline 19 & 4.323 & 3.975 & -4.107 & 0.7 & 0.7827 & 0.1957 \\
\hline 20 & 4.323 & 0 & 4.107 & 1.2 & 1.6741 & 0.4293 \\
\hline 21 & 4.323 & -3.975 & 0 & 0.2 & 0.1858 & 0.0478 \\
\hline 22 & 4.323 & 3.975 & 0 & 0.7 & 0.7549 & 0.2455 \\
\hline 23 & 4.323 & 0 & 4.107 & 0.2 & 0.3217 & 0.0847 \\
\hline 24 & 4.323 & -3.975 & -4.107 & 1.2 & 2.0382 & 0.5155 \\
\hline 25 & 4.323 & 3.975 & 4.107 & 0.2 & 0.2489 & 0.0655 \\
\hline 26 & 4.323 & 0 & 0 & 0.7 & 0.8438 & 0.2073 \\
\hline 27 & 0 & 0 & 0 & Original value & 1.9278 & 0.5130 \\
\hline
\end{tabular}

earthquake. PGAs of the 15 synthesized ground motions were adjusted to $0.2 \mathrm{~g}, 0.7 \mathrm{~g}$, and $1.2 \mathrm{~g}$, respectively, and 45 ground motions were obtained. 26 combinations were acquired through the experimental design of 3 levels of $F_{1}, F_{2}$, $F_{3}$ and PGA, the above 45 ground motions were used to conduct 390 dynamic response analysis for each combination. In addition, a 27th combination was added, and the 15 original ground motions were used for dynamic response analysis, and a total of 405 dynamic response analysis were conducted. The analysis results are shown in Table 5 .

According to the dynamic response analysis results of the first 26 combinations, equations (7) and (8) were solved, and the regression coefficients are shown in Table 6.

\section{Embankment Seismic Fragility Assessment}

\subsection{Embankment Seismic Damage Analysis}

4.1.1. Impact of PGA. Based on the dynamic response analysis results, the embankment seismic damage grades are basically intact and minor damage when PGA $=0.2 \mathrm{~g}$, but due to the impacts of the structural parameters and rupture fault distances, $\varepsilon_{\max }$ has a high dispersion, ranging from 0.1219 to 0.4532 . With the increase of PGA, the embankment seismic damage is intensified, most of the damage grades are minor damage and moderate damage when PGA $=0.7 \mathrm{~g}$, and $\varepsilon_{\text {max }}$ ranges from 0.5791 to 1.0816 ; the damage grades are all severe damage and destruction when $\mathrm{PGA}=1.2 \mathrm{~g}$, and $\varepsilon_{\max }$ ranges from 1.5007 to 2.3301. Figure 6 shows the embankment seismic damages of $R=10 \mathrm{~km}$ for the $11 \mathrm{th}, 14 \mathrm{th}$, 18 th, and 27 th combinations. It can be seen that when the structural parameters and rupture fault distances are constant, the damage grade and PGA have a positive correlation. Embankment seismic damages are mainly manifested by the lateral displacement on the top surface of the embankment and cracks (red solid lines in the figures). Among them, all the cracks originate from the deformation of the slope and extend to the interior of the embankment. The lateral displacements and length of the cracks are also positively correlated [57-59].

4.1.2. Impact of the Rupture Fault Distance. Figure 7 shows the embankment seismic damages of the 11th combination with $R=1 \mathrm{~km}, 4 \mathrm{~km}, 7 \mathrm{~km}, 10 \mathrm{~km}, 13 \mathrm{~km}$, and $15 \mathrm{~km}$. Combined with the analysis results of other combinations, it is noticeable that the correlation between the rupture fault distance and $\varepsilon_{\max }$ is not obvious when the structural parameters and PGA are constant. Figure 8 shows the embankment seismic damages of the 27th combination with $R=1 \mathrm{~km}, 4 \mathrm{~km}, 7 \mathrm{~km}, 10 \mathrm{~km}, 13 \mathrm{~km}$, and $15 \mathrm{~km}$. It can be seen that different rupture fault distances correspond to different seismic damages to the same structure in the same earthquake, i.e., the smaller the rupture fault distances, the more severe the damages; and the larger the rupture fault distances, the milder the damages. 
TABLE 6: Regression coefficients of equations (7) and (8).

\begin{tabular}{lcccccccc}
\hline Regression coefficients & $\alpha_{0}$ & $\alpha_{1}$ & $\alpha_{2}$ & $\alpha_{3}$ & $\alpha_{4}$ & $\alpha_{5}$ & $\alpha_{6}$ \\
\hline Values & 0.25065 & 0.01612 & 0.04187 & 0.02290 & 0.35272 & -0.00330 & -0.00527 & -0.00253 \\
Regression coefficients & $\alpha_{8}$ & $\alpha_{9}$ & $\alpha_{10}$ & $\alpha_{11}$ & $\alpha_{012}$ & $\alpha_{13}$ & $\alpha_{14}$ & $\varepsilon_{1}$ \\
Values & 0.91883 & -0.00332 & -0.00396 & -0.02488 & -0.00384 & -0.06253 & -0.03349 & 0.0342 \\
Regression coefficients & $\beta_{0}$ & $\beta_{1}$ & $\beta_{2}$ & $\beta_{3}$ & $\beta_{4}$ & $\beta_{5}$ & $\beta_{6}$ & $\beta_{7}$ \\
Values & 0.06346 & 0.00424 & 0.01102 & -0.00654 & 0.09044 & 0.00083 & 0.00132 & -0.00067 \\
Regression coefficients & $\beta_{8}$ & $\beta_{1}$ & $\beta_{2}$ & $\beta_{3}$ & $\beta_{4}$ & $\beta_{5}$ & $\beta_{6}$ & $\varepsilon_{2}$ \\
Values & 0.24502 & -0.00085 & -0.00102 & -0.00479 & -0.00097 & 0.01645 & -0.00837 & 0.0169 \\
\hline
\end{tabular}

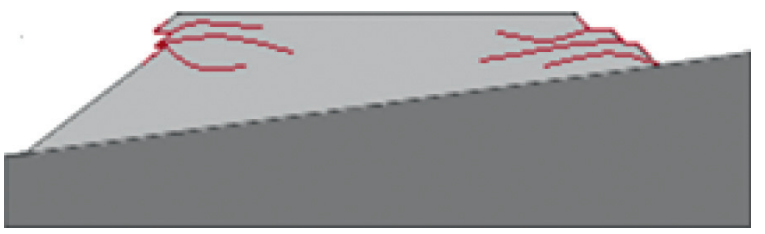

(a)

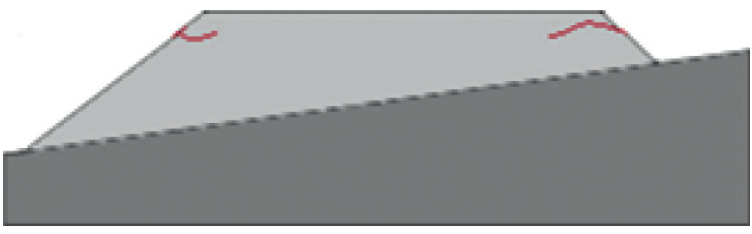

(c)

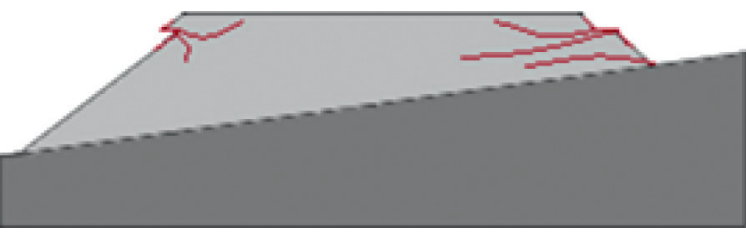

(b)

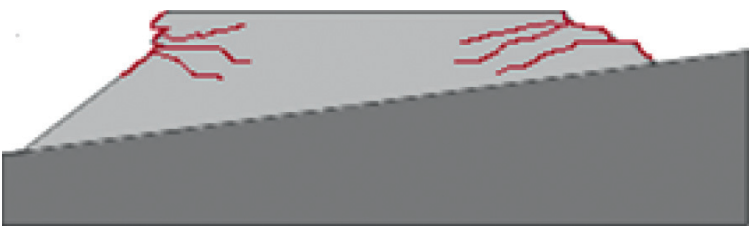

(d)

Figure 6: Embankment seismic damages of $R=10 \mathrm{~km}$. (a) Seismic damages of the 11 th combination $(\mathrm{F} 1=\mathrm{F} 2=\mathrm{F} 3=0, \mathrm{PGA}=1.2 \mathrm{~g}$, and $\varepsilon_{\max }=1.8433$ ). (b) Seismic damages of the 14th combination $\left(\mathrm{F} 1=\mathrm{F} 2=\mathrm{F} 3=0\right.$, PGA $=0.7 \mathrm{~g}$, and $\left.\varepsilon_{\max }=0.6874\right)$. (c) Seismic damages of the 18 th combination $\left(F 1=F 2=F 3=0, P G A=1.2 \mathrm{~g}\right.$, and $\left.\varepsilon_{\max }=0.2687\right)$. (d) Seismic damages of the 27 th $\operatorname{combination}(F 1=F 2=F 3=0$, $\mathrm{PGA}=1.197 \mathrm{~g}$, and $\left.\varepsilon_{\max }=1.8075\right)$.

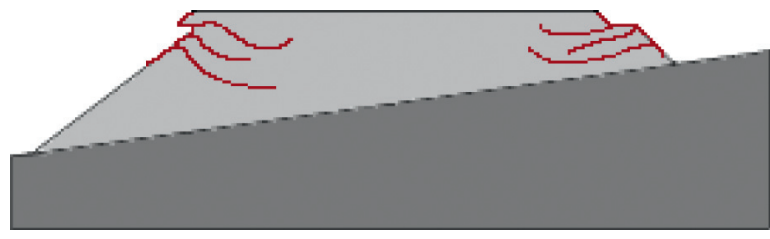

(a)

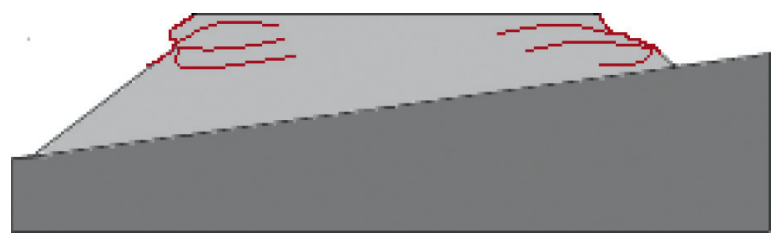

(c)

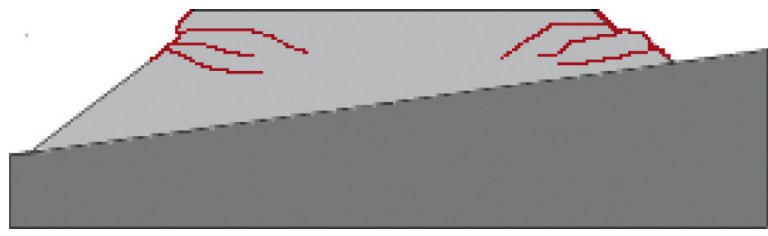

(e)

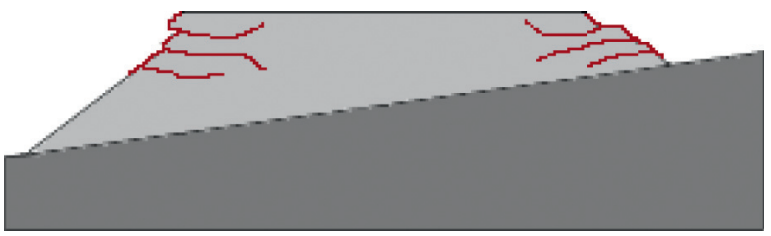

(b)

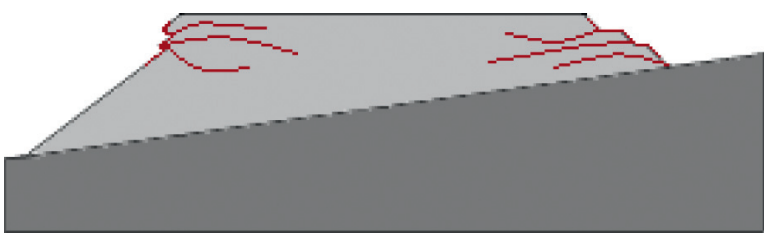

(d)

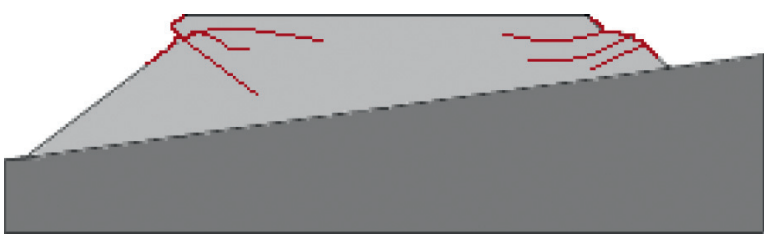

(f)

Figure 7: Embankment seismic damages of the 11 th combination $\left(F_{1}=F_{2}=F_{3}=0\right.$ and PGA $\left.=1.2 \mathrm{~g}\right)$. (a) Seismic damages of $R=1 \mathrm{~km}$ $\left(\varepsilon_{\max }=1.7913\right)$. (b) Seismic damages of $R=4 \mathrm{~km}\left(\varepsilon_{\max }=1.8931\right)$. (c) Seismic damages of $R=7 \mathrm{~km}\left(\varepsilon_{\max }=1.9736\right)$. (d) Seismic damages of $R=10 \mathrm{~km}\left(\varepsilon_{\max }=1.8433\right)$. (e) Seismic damages of $R=13 \mathrm{~km}\left(\varepsilon_{\max }=1.8408\right)$. (f) Seismic damages of $R=15 \mathrm{~km}\left(\varepsilon_{\max }=1.8297\right)$. 


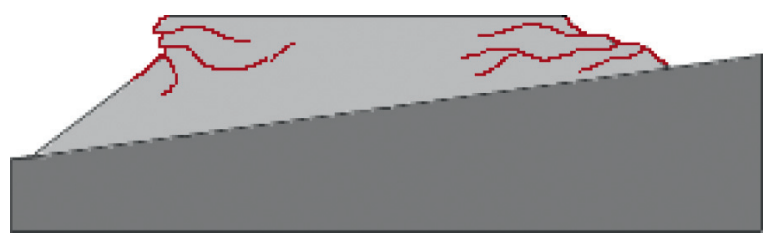

(a)

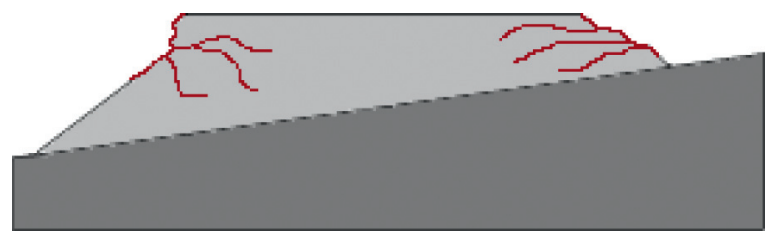

(c)

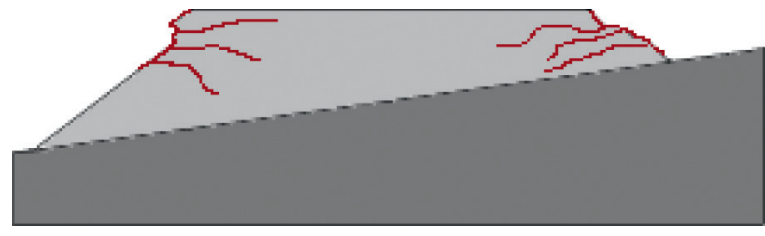

(e)

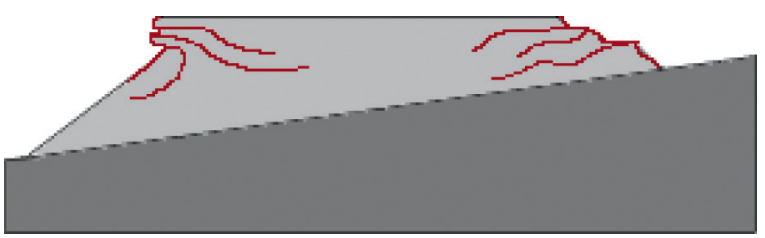

(b)

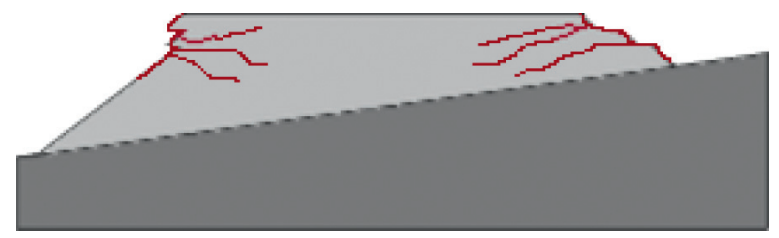

(d)

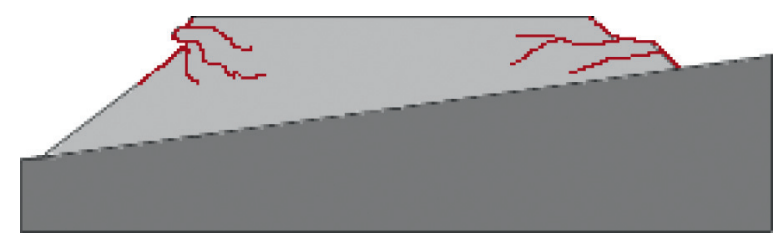

(f)

FIGURE 8: Embankment seismic damages of the 27th combination $\left(F_{1}=F_{2}=F_{3}=0\right.$ and PGA= original value). (a) Seismic damages of $R=1 \mathrm{~km}\left(\mathrm{PGA}=1.233 \mathrm{~g}\right.$ and $\left.\varepsilon_{\max }=0.2687\right)$. (b) Seismic damages of $R=4 \mathrm{~km}$ (PGA $=1.221 \mathrm{~g}$ and $\left.\varepsilon_{\max }=2.0836\right)$. (c) Seismic damages of $R=7 \mathrm{~km}\left(\mathrm{PGA}=1.209 \mathrm{~g}\right.$ and $\left.\varepsilon_{\max }=1.9533\right)$. (d) Seismic damages of $R=10 \mathrm{~km}$ (PGA $=1.197 \mathrm{~g}$ and $\left.\varepsilon_{\max }=1.8075\right)$. (e) Seismic damages of $R=13 \mathrm{~km}\left(\mathrm{PGA}=1.182 \mathrm{~g}\right.$ and $\left.\varepsilon_{\max }=1.6656\right)$. (f) Seismic damages of $R=15 \mathrm{~km}\left(\mathrm{PGA}=1.173 \mathrm{~g}\right.$ and $\left.\varepsilon_{\max }=1.5447\right)$.

4.1.3. Energy Dissipation. Figure 9 shows the embankment energy dissipations of the 27 th combination with $R=1 \mathrm{~km}$ to $15 \mathrm{~km}$, respectively. It can be seen that the energy dissipations are between $3.048 \times 10^{6}$ and $4.626 \times 10^{6} \mathrm{~N} \cdot \mathrm{m}$; the smaller the rupture fault distances, the greater the energy dissipations; and the larger the rupture fault distances, the smaller the energy dissipations [59].

4.2. Embankment Seismic Fragility Curves. By inputting the 10,000 sets of structural parameter combinations obtained in Section 3.3 to equation (7), obtain the probabilistic seismic demand model of the embankment [60-62], as shown in the following equation:

$$
\ln \varepsilon_{\max }=\ln 1.5897+1.3457 \ln P G A .
$$

Substituting equation (7) into the classical calculation formula of the seismic fragility, the following equation is obtained:

$$
R_{f}=\Phi\left(\frac{\ln \left(1.5897 P G A^{1.3457} / S_{f}\right)}{0.5}\right),
$$

where $R_{f}$ is the exceeding probability of the embankment seismic damage grade $f, S_{f}$ is the structural performance level shown in Table 2, that is, $S_{f}=2.00$ when $f$ is destruction, $S_{f}=1.20$ when $f$ is severe damage, $S_{f}=0.60$ when $f$ is moderate damage, and $S_{f}=0.30$ when $f$ is minor damage. The embankment seismic fragility curves plotted from equation (10) are shown in Figure 10.

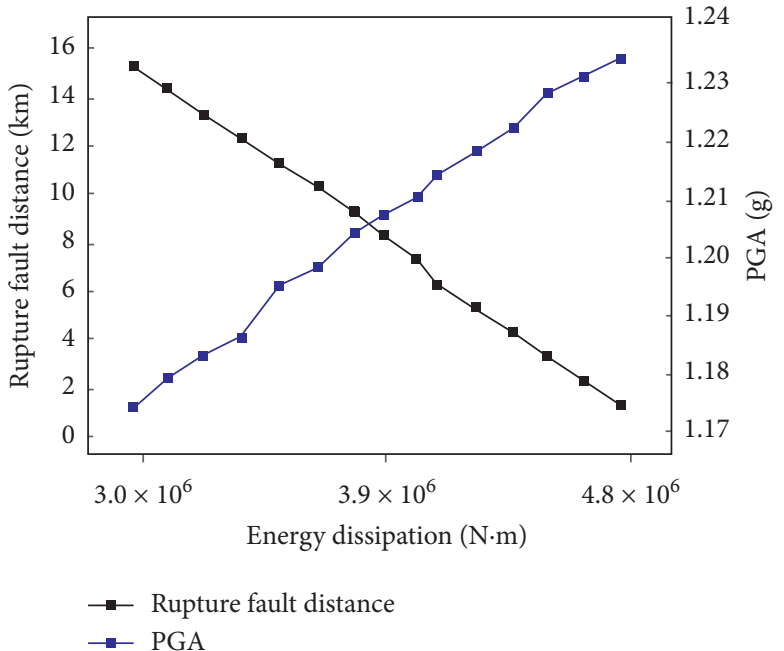

FIGURE 9: Embankment energy dissipations of the 27th combination $\left(\mathrm{F}_{1}=\mathrm{F}_{2}=\mathrm{F}_{3}=0\right.$ and $\mathrm{PGA}=$ original value $)$.

Exceeding probabilities of each embankment seismic damage grade under different PGAs were calculated according to Figure $10[63,64]$, as shown in Table 7.

It can be seen from Table 7 that the exceeding probability of the severe damage is 0.713094 and of the destruction is 0.323044 when $\mathrm{PGA}=1.0 \mathrm{~g}$, while according to Yin et al. [47], the two exceeding probabilities were 0.634172 and 0.265767, respectively. According to Yu et al. [65], Zhang et al. [66], and Luo et al. [67], the exceeding probability of each seismic damage grade of embankments at the epicenter 


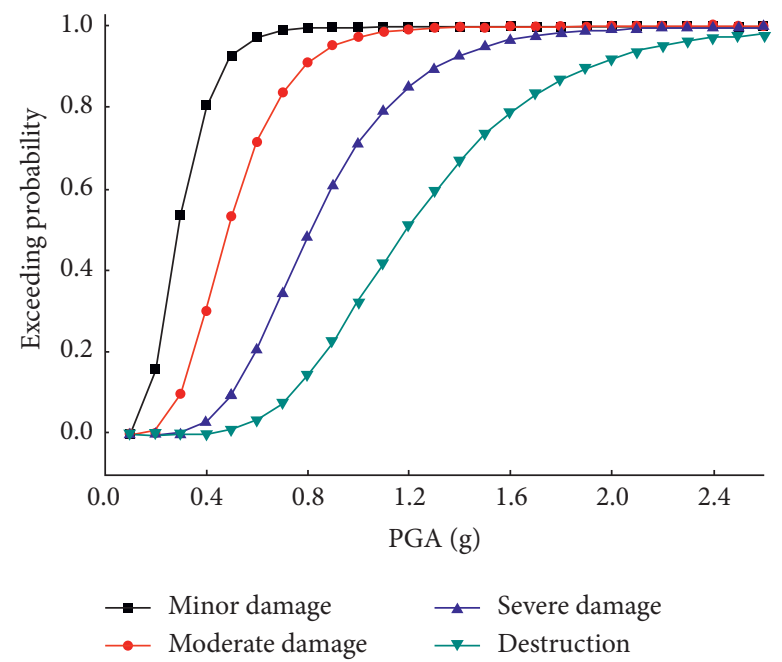

Figure 10: Embankment seismic fragility curves.

TABLE 7: Exceeding probabilities of each embankment seismic damage grade under different PGAs.

\begin{tabular}{|c|c|c|c|c|c|}
\hline \multicolumn{2}{|l|}{ Embankment seismic damage grades } & \multirow{2}{*}{$\begin{array}{c}\begin{array}{c}\text { Minor } \\
\text { damage }\end{array} \\
0.002104\end{array}$} & \multirow{2}{*}{$\begin{array}{c}\begin{array}{c}\text { Severe } \\
\text { damage }\end{array} \\
0.000001\end{array}$} & \multicolumn{2}{|l|}{ Destruction } \\
\hline & $0.1 \mathrm{~g}$ & & & 0.000000 & 0.000000 \\
\hline & $0.2 \mathrm{~g}$ & 0.159478 & 0.008588 & 0.000008 & 0.000000 \\
\hline & $0.3 \mathrm{~g}$ & 0.537709 & 0.098243 & 0.003704 & 0.000108 \\
\hline & $0.4 \mathrm{~g}$ & 0.807558 & 0.302451 & 0.028477 & 0.001721 \\
\hline & $0.5 \mathrm{~g}$ & 0.929151 & 0.533156 & 0.096272 & 0.010043 \\
\hline & $0.6 \mathrm{~g}$ & 0.975014 & 0.716984 & 0.208284 & 0.033324 \\
\hline & $0.7 \mathrm{~g}$ & 0.991227 & 0.838616 & 0.345497 & 0.077926 \\
\hline & $0.8 \mathrm{~g}$ & 0.996876 & 0.911199 & 0.484796 & 0.144624 \\
\hline & $0.9 \mathrm{~g}$ & 0.998861 & 0.952061 & 0.609832 & 0.228810 \\
\hline & $1.0 \mathrm{~g}$ & 0.999574 & 0.974337 & 0.713094 & 0.323044 \\
\hline & $1.1 \mathrm{~g}$ & 0.999836 & 0.986282 & 0.793597 & 0.419690 \\
\hline & $1.2 \mathrm{~g}$ & 0.999935 & 0.992645 & 0.853863 & 0.512563 \\
\hline Exceeding probabilities of each embankment seismic damage grade under & $1.3 \mathrm{~g}$ & 0.999973 & 0.996033 & 0.897704 & 0.597516 \\
\hline different PGAs & $1.4 \mathrm{~g}$ & 0.999989 & 0.997844 & 0.928952 & 0.672338 \\
\hline & $1.5 \mathrm{~g}$ & 0.999995 & 0.998817 & 0.950907 & 0.736328 \\
\hline & $1.6 \mathrm{~g}$ & 0.999998 & 0.999345 & 0.966181 & 0.789811 \\
\hline & $1.7 \mathrm{~g}$ & 0.999999 & 0.999633 & 0.976736 & 0.833710 \\
\hline & $1.8 \mathrm{~g}$ & 1.000000 & 0.999793 & 0.984000 & 0.869231 \\
\hline & $1.9 \mathrm{~g}$ & 1.000000 & 0.999882 & 0.988987 & 0.897651 \\
\hline & $2.0 \mathrm{~g}$ & 1.000000 & 0.999932 & 0.992408 & 0.920187 \\
\hline & $2.1 \mathrm{~g}$ & 1.000000 & 0.999960 & 0.994756 & 0.937932 \\
\hline & $2.2 \mathrm{~g}$ & 1.000000 & 0.999977 & 0.996368 & 0.951829 \\
\hline & $2.3 \mathrm{~g}$ & 1.000000 & 0.999986 & 0.997477 & 0.962665 \\
\hline & $2.4 \mathrm{~g}$ & 1.000000 & 0.999992 & 0.998242 & 0.971088 \\
\hline & $2.5 \mathrm{~g}$ & 1.000000 & 0.999995 & 0.998771 & 0.977620 \\
\hline & $2.6 \mathrm{~g}$ & 1.000000 & 0.999997 & 0.999138 & 0.982676 \\
\hline
\end{tabular}

of the Chi-Chi earthquake $(P G A=0.977 \mathrm{~g})$ is shown in Table 8

By comparing Tables 7 and 8 , it can be seen that the research results of this paper are consistent with the actual embankment seismic damage conditions of the Chi-Chi earthquake, which indicates that the method proposed in this paper is scientific and reasonable. It also shows that it would obviously overestimate the seismic performance in 
TABLE 8: Exceeding probability of each seismic damage grade at the epicenter of the Chi-Chi earthquake [65-67].

\begin{tabular}{lcccc}
\hline Embankment seismic damage grades & Minor damage & Moderate damage & Severe damage & Destruction \\
\hline Exceeding probabilities & 0.999851 & 0.963846 & 0.672483 & 0.298452 \\
\hline
\end{tabular}

the embankment seismic fragility assessment without considering the uncertainties of the ground motions and structural parameters.

\section{Conclusion}

In this paper, stochastic modeling and artificial synthesizing method of the near-fault pulse-like ground motions was proposed, and a total of 12 structural parameters were selected as the design variables by taking the Xi'an-Baoji expressway K1125 + 470 embankment as the research object. In order to eliminate the linear correlations of these parameters, 3 principal components with large impacts on the embankment seismic fragility were extracted based on the principal component analysis. Mapping relationships among the principal components and embankment seismic damages were analyzed using the uniform design response surface method, and the seismic fragility assessment was carried out and the fragility curves were plotted. The following conclusions can be drawn:

(1) Since the orientation of the apparatus in a seismic station is arbitrary, the recorded ground motions at the time of the earthquake are not necessarily the maximum, especially for the near-fault pulselike ground motions, the seismic intensities in different directions are obviously different. The stochastic pulse models of different rupture fault distances were established by considering the directional impacts of the pulse-like ground motions, and 15 ground motions with the rupture fault distance ranging from 1 to $15 \mathrm{~km}$ were synthesized by taking the Chi-Chi earthquake in Taiwan, China, as an example.

(2) Embankment seismic damages are mainly manifested by the lateral displacement on the top surface of the embankment and cracks. All the cracks originate from the deformation of the slope and extend to the interior of the embankment, and the lateral displacements and length of the cracks are positively correlated. It can also be seen that different rupture fault distances correspond to different seismic damages and energy dissipations to the same structure in the same earthquake, i.e., the smaller the rupture fault distances, the more severe the damages and the greater the energy dissipations; and the larger the rupture fault distances, the milder the damages and the smaller the energy dissipations.

(3) The research results of the embankment seismic fragility assessment are consistent with the actual embankment seismic damage conditions of the ChiChi earthquake, indicating that the method proposed in this paper is scientific and reasonable. It also shows that it would obviously overestimate the seismic performance in the embankment seismic fragility assessment without considering the uncertainties of the ground motions and structural parameters.

(4) Supporting structures such as retaining wall and antislide pile have positive effects on improving the embankment seismic performance. Defining the characteristics of the damages of the supporting structure-embankment fill-soil foundation system under different ground motions is a prerequisite to uncover the dynamic coupling mechanism between the supporting structure and the embankment, but relevant researches have not been carried out yet.

\section{Data Availability}

All the data generated or analyzed during this study are included within this article.

\section{Conflicts of Interest}

The authors declare that there are no conflicts of interest regarding the work submitted.

\section{Acknowledgments}

This research was supported by the National Natural Science Foundation of China (Grant no. 51808327) and the Natural Science Foundation of Shandong Province (Grant no. ZR2019PEE016).

\section{References}

[1] D. Wang, Z. Fan, S. Hao, and D. Zhao, "An evolutionary power spectrum model of fully nonstationary seismic ground motion," Soil Dynamics and Earthquake Engineering, vol. 105, pp. 1-10, 2018.

[2] J. Ma, X. J. Feng, G. Y. Li, and X. N. Li, "New insights from analysis of historical texts on the 1568 Northeast Xi'an earthquake, Shaanxi, China," International Journal of Disaster Risk Reduction, vol. 44, p. 101417, 2019.

[3] T. Chen, Z. J. Wu, Y. H. Mu, P. Wang, and Q. Y. Zhu, "Numerical analysis of seismic site effects in loess region of western China under strong earthquake excitations," Shock and Vibration, vol. 2020, Article ID 3918352, 12 pages, 2020.

[4] P. G. Somerville, N. F. Smith, R. W. Graves, and N. A. Abrahamson, "Modification of empirical strong ground motion attenuation relations to include the amplitude and duration effects of rupture directivity," Seismological Research Letters, vol. 68, no. 1, pp. 199-222, 1997.

[5] P. Tothong, C. A. Cornell, and J. W. Baker, "Explicit directivity-pulse inclusion in probabilistic seismic hazard analysis," Earthquake Spectra, vol. 23, no. 4, pp. 867-891, 2007. 
[6] S. K. Shahi and J. W. Baker, "An empirically calibrated framework for including the effects of near-fault directivity in probabilistic seismic hazard analysis," Bulletin of the Seismological Society of America, vol. 101, no. 2, pp. 742-755, 2011.

[7] S. J. Li, C. Wu, and F. Kong, "Shaking table model test and seismic performance analysis of a high-rise RC shear wall structure," Shock and Vibration, vol. 2019, Article ID 6189873, 17 pages, 2019.

[8] K. Ji, R. Wen, Y. Ren, and Y. P. Dhakal, "Nonlinear seismic site response classification using K-means clustering algorithm: case study of the September 6, 2018 Mw6.6 Hokkaido Iburi-Tobu earthquake, Japan," Soil Dynamics and Earthquake Engineering, vol. 128, p. 105907, 2020.

[9] X.-q. Zhao, F.-d. Wang, S. Verheyden, J. Liu-zeng, and G. Zhang, "Earthquake-related speleothem damages: observations from the $2008 \mathrm{Mw} 7.9$ Wenchuan, China," Geomorphology, vol. 358, p. 107130, 2020.

[10] X. B. Hu, C. Lu, and X. Q. Zhu, "A simplified model for dynamic response analysis of framed self-centering wall structures under seismic excitations," Shock and Vibration, vol. 2019, Article ID 2360150, 14 pages, 2019.

[11] Y.-Y. Ko and H.-H. Yang, "Deriving seismic fragility curves for sheet-pile wharves using finite element analysis," Soil Dynamics and Earthquake Engineering, vol. 123, pp. 265-277, 2019.

[12] F. O. Strasser, N. A. Abrahamson, and J. J. Bommer, "Sigma: issues, insights, and challenges," Seismological Research Letters, vol. 80, no. 1, pp. 40-56, 2009.

[13] S. Hamidpour and M. Soltani, "Probabilistic assessment of ground motions intensity considering soil properties uncertainty," Soil Dynamics and Earthquake Engineering, vol. 90, pp. 158-168, 2016.

[14] Y. Zhang, X. Zhi, and F. Fan, "Fragility analysis of reticulated domes subjected to multiple earthquakes," Engineering Structures, vol. 211, p. 110450, 2020.

[15] H. Pan, L. Tian, X. Fu, and H. Li, "Sensitivities of the seismic response and fragility estimate of a transmission tower to structural and ground motion uncertainties," Journal of Constructional Steel Research, vol. 167, p. 105941, 2020.

[16] C. Yin, Y. Li, and F. F. Liu, "Probability risk assessment and management of embankment seismic damages based on CPSHA-PSDA," Iranian Journal of Science and Technology, Transaction A: Science, vol. 91, pp. 129-147, 2019.

[17] X. Bao, M.-H. Zhang, and C.-H. Zhai, "Fragility analysis of a containment structure under far-fault and near-fault seismic sequences considering post-mainshock damage states," Engineering Structures, vol. 198, p. 109511, 2019.

[18] J. C. He, F. Han, S. S. Zheng, X. K. Xie, and Y. L. Cai, "Seismic vulnerability analysis of multi-age buried steel pipes in an acidic soil environment," Journal of Tianjin University (Science and Technology), vol. 53, no. 9, pp. 881-889, 2020, (in Chinese).

[19] H. Zhou, X. H. Wang, C. D. He, and C. X. Huang, "Seismic response of a tunnel embedded in compacted clay through large-scale shake table testing," Shock and Vibration, vol. 2018, Article ID 5968431, 17 pages, 2018.

[20] L. Tian, H. Pan, and R. Ma, "Probabilistic seismic demand model and fragility analysis of transmission tower subjected to near-field ground motions," Journal of Constructional Steel Research, vol. 156, pp. 266-275, 2019.

[21] J. X. Sheng, H. M. Li, and H. C. Ma, "Seismic fragility analysis for frame structure under near-fault forward directivity ground motions," China Civil Engineering Journal, vol. 51, no. 12, pp. 81-89, 2018, (in Chinese).

[22] M. R. Salami, M. M. Kashani, and K. Goda, "Influence of advanced structural modeling technique, mainshock-aftershock sequences, and ground-motion types on seismic fragility of low-rise RC structures," Soil Dynamics and Earthquake Engineering, vol. 117, pp. 263-279, 2019.

[23] M. Abyani, M. R. Bahaari, M. Zarrin, and M. Nasseri, "Effects of sample size of ground motions on seismic fragility analysis of offshore jacket platforms using Genetic Algorithm," Ocean Engineering, vol. 189, p. 106326, 2019.

[24] D. Yang and J. Zhou, "A stochastic model and synthesis for near-fault impulsive ground motions," Earthquake Engineering \& Structural Dynamics, vol. 44, no. 2, pp. 243-264, 2015.

[25] T. V. Hung and O. Kiyomiya, "Use of the stochastic-source model to simulate ground motion and response spectra in northern Vietnam," Journal of Asian Earth Sciences, vol. 62, pp. 485-500, 2013.

[26] J. L. Zhou, D. X. Yang, G. H. Chen, and C. R. Han, “Dynamic reliability analysis of structures subjected to near-fault strong ground motions," Journal of Building Structures, vol. 37, no. 7, pp. 136-143, 2016, (in Chinese).

[27] A. M. Y. Al-Tayari, S. Y. Chen, and Z. Sun, "A coupled torsional-transition nonlinear vibration and dynamic model of a two-stage helical gearbox reducer for electric vehicles," Shock and Vibration, vol. 2020, Article ID 8838521, 25 pages, 2020.

[28] P. Kumar and A. Samanta, "Seismic fragility assessment of existing reinforced concrete buildings in Patna, India," Structures, vol. 27, pp. 54-69, 2020.

[29] H. H. Li and L. F. Li, "Bridge fragility analysis based on an improved uniform design-response surface methodology," Journal of Vibration and Shock, vol. 37, no. 22, pp. 245-254, 2018, (in Chinese).

[30] B. Bai, H. Li, W. Zhang, and Y. Cui, "Application of extremum response surface method-based improved substructure component modal synthesis in mistuned turbine bladed disk," Journal of Sound and Vibration, vol. 472, p. 115210, 2020.

[31] J. Seo and D. G. Linzell, "Use of response surface metamodels to generate system level fragilities for existing curved steel bridges," Engineering Structures, vol. 52, pp. 642-653, 2013.

[32] S. L. Fan, S. Tian, and J. Y. Chen, "Seismic fragility analysis on arch dam based on response surface method," Yangtze River, vol. 50, no. 7, pp. 160-164, 2019, (In Chinese).

[33] S. K. Saha, V. Matsagar, and S. Chakraborty, "Uncertainty quantification and seismic fragility of base-isolated liquid storage tanks using response surface models," Probabilistic Engineering Mechanics, vol. 43, pp. 20-35, 2016.

[34] T.-T. Tran, A.-T. Cao, T.-H.-X. Nguyen, and D. Kim, "Fragility assessment for electric cabinet in nuclear power plant using response surface methodology," Nuclear Engineering and Technology, vol. 51, no. 3, pp. 894-903, 2019.

[35] N. Buratti, B. Ferracuti, and M. Savoia, "Response surface with random factors for seismic fragility of reinforced concrete frames," Structural Safety, vol. 32, no. 1, pp. 42-51, 2010.

[36] J. Ma and Y. Yuan, "Dimension reduction of image deep feature using PCA," Journal of Visual Communication and Image Representation, vol. 63, p. 102578, 2019.

[37] L.-Y. Chen and S. Lee, "Breaking the curse of dimensionality in conditional moment inequalities for discrete choice models," Journal of Econometrics, vol. 210, no. 2, pp. 482-497, 2019. 
[38] F. Zhang, S. Li, J. Wang, and J. Zhang, "Effects of fault rupture on seismic responses of fault-crossing simply-supported highway bridges," Engineering Structures, vol. 206, p. 110104, 2020.

[39] J. L. Zhou, C. C. Liu, and C. B. Ren, "Chaos control of a multidimensional chaotic mapping system by modified stability transformation method," Journal of Vibroengineering, vol. 19, no. 2, pp. 1103-1115, 2017.

[40] S. S. Yaghmaei, S. Neekmanesh, and G. J. Ruiz, "Evaluation of the coefficient method for estimation of maximum roof displacement demand of existing buildings subjected to nearfault ground motions," Soil Dynamics and Earthquake Engineering, vol. 121, pp. 276-280, 2019.

[41] P. Cacciola and A. Tombari, "A stochastic ground motion model for the urban environment," Probabilistic Engineering Mechanics, vol. 59, p. 103026, 2020.

[42] C. Vetter and A. A. Taflanidis, "Comparison of alternative stochastic ground motion models for seismic risk characterization," Soil Dynamics and Earthquake Engineering, vol. 58, pp. 48-65, 2014.

[43] C.-C. Chou, A.-P. Jeng, C.-P. Chu, C.-H. Chang, and R.-G. Wang, "Generation and visualization of earthquake drill scripts for first responders using ontology and serious game platforms," Advanced Engineering Informatics, vol. 38, pp. 538-554, 2018.

[44] H. Y. Jia, X. L. Lan, H. Chen, S. X. Zheng, X. Li, and Y. S. Zhang, "Synthesis of non-stationary seismic waves based on phase difference spectrum and its application," Journal of Southwest Jiao Tong University, vol. 54, no. 3, pp. 453-460, 2019, (in Chinese).

[45] Y. Yu, I. P. Damians, and R. J. Bathurst, "Influence of choice of FLAC and PLAXIS interface models on reinforced soilstructure interactions," Computers and Geotechnics, vol. 65, pp. 164-174, 2015.

[46] H. Horiguchi, M. Kurosawa, and T. Shiba, "Posterior capsule rupture with FLACS due to erroneous interpretation of a high OCT intensity area in anterior vitreous," American Journal of Ophthalmology Case Reports, vol. 19, p. 100811, 2020.

[47] C. Yin, J. Shi, F. F. Liu, W. P. Tian, and W. Tian, "Embankment seismic fragility assessment based on IDA-PSDA," China Journal of Highway and Transportation, vol. 30, no. 5, pp. 28-37, 2017, (in Chinese).

[48] Z. P. Song, J. C. Mao, X. X. Tian, Y. W. Zhang, and J. B. Wang, "Optimization analysis of controlled blasting for passing through houses at close range in super-large section tunnels," Shock and Vibration, vol. 2019, Article ID 1941436, 16 pages, 2019.

[49] T. Li, J. Lin, and J. Liu, "Analysis of time-dependent seismic fragility of the offshore bridge under the action of scour and chloride ion corrosion," Structures, vol. 28, pp. 1785-1801, 2020.

[50] J.-M. Zhang, Z. Yang, X. Gao, and J. Zhang, "Geotechnical aspects and seismic damage of the 156-m-high Zipingpu concrete-faced rockfill dam following the Ms 8.0 Wenchuan earthquake," Soil Dynamics and Earthquake Engineering, vol. 76, pp. 145-156, 2015.

[51] P. Lin, B. Huang, Q. Li, and R. Wang, "Hazard and seismic reinforcement analysis for typical large dams following the Wenchuan earthquake," Engineering Geology, vol. 194, pp. 86-97, 2015.

[52] B. Han, L. Zdravkovic, S. Kontoe, and D. M. G. Taborda, "Numerical investigation of the response of the Yele rockfill dam during the 2008 Wenchuan earthquake," Soil Dynamics and Earthquake Engineering, vol. 88, pp. 124-142, 2016.
[53] C. Xu, S. Peng, X. Liu, C. Wang, and Q. Xu, "Analysis of the seismic behavior of CFRP-strengthened seismic-damaged composite steel-concrete frame joints," Journal of Building Engineering, vol. 28, p. 101057, 2020.

[54] A. Hinrichs, J. Prochno, and M. Ullrich, "The curse of dimensionality for numerical integration on general domains," Journal of Complexity, vol. 50, pp. 25-42, 2019.

[55] G. Guo and L. Qin, D. X. Yang, D. Yang, and Y. Liu, "Dimensional response analysis of rocking wall-frame building structures with control devices subjected to near-fault pulselike ground motions," Engineering Structures, vol. 220, p. 110842, 2020.

[56] K. Dai, X. Luo, Y. Lu et al., "Seismic collision potential of adjacent base-isolated buildings with corridor bridges subjected to bidirectional near-fault pulse-like ground motions," Soil Dynamics and Earthquake Engineering, vol. 135, p. 106202, 2020.

[57] B. Li, L. X. Zhang, Q. L. Zhang, and S. M. Yang, “An EEMDbased denoising method for seismic signal of high arch dam combining wavelet with singular spectrum analysis," Shock and Vibration, vol. 2019, Article ID 4937595, 9 pages, 2019.

[58] Z. Q. Huang, X. Peng, G. Li, and L. Hao, "Response of a twodegree-of-freedom vibration system with rough contact interfaces," Shock and Vibration, vol. 2019, Article ID 1691582, 13 pages, 2019.

[59] Y. Wang, Z. F. Li, Z. Y. Wu, X. F. Fan, and Z. Y. Tian, "Seismic fragility analysis of gravity dams considering the fuzziness of damage states thresholds," Advanced Engineering Sciences, vol. 52, Article ID 110120, 2020, (in Chinese).

[60] S. Yoon, D. H. Lee, and H.-J. Jung, "Seismic fragility analysis of a buried pipeline structure considering uncertainty of soil parameters," International Journal of Pressure Vessels and Piping, vol. 175, p. 103932, 2019.

[61] Z. Zhong, Y. Shen, M. Zhao, L. Li, X. Du, and H. Hao, "Seismic fragility assessment of the Daikai subway station in layered soil," Soil Dynamics and Earthquake Engineering, vol. 132, p. 106044, 2020.

[62] N. Xiang, X. Chen, and M. S. Alam, "Probabilistic seismic fragility and loss analysis of concrete bridge piers with superelastic shape memory alloy-steel coupled reinforcing bars," Engineering Structures, vol. 207, p. 110229, 2020.

[63] G. Andreotti and C. G. Lai, "Use of fragility curves to assess the seismic vulnerability in the risk analysis of mountain tunnels," Tunnelling and Underground Space Technology, vol. 91, p. 103008, 2019.

[64] A. Kalantari and H. Roohbakhsh, "Expected seismic fragility of code-conforming RC moment resisting frames under twin seismic events," Journal of Building Engineering, vol. 28, p. 101098, 2020.

[65] H. M. Yu, J. D. Xu, S. L. Zhang, and B. Pan, "The statistical analysis of building vulnerability research on chi-chi earthquake," Journal of Institute of Disaster-Prevention Science and Technology, vol. 8, no. 4, pp. 17-20, 2006, (in Chinese).

[66] Z. Zhang, J. L. Hu, and H. B. Liu, "Assessment of seismic liquefaction-induced lateral spreading in gentle slope field based on Bayesian network: a case of the Chi-Chi earthquake, Taiwan," Journal of Natural Disasters, vol. 27, no. 6, pp. 127-132, 2018, (in Chinese).

[67] Q. B. Luo, X. L. Chen, M. T. Gao, Z. C. Li, and T. F. Li, "Analysis of near-fault velocity pulses in the Chi-Chi earthquake," Recent Developments in World Seismology, vol. 490, pp. 2-10, 2019, (in Chinese). 